\title{
LA ADVERSA FORTUNA EN EL VIAJE DE CABEZA DE VACA POR TIERRAS NORTEÑAS
}

\author{
TRINIDAD BARRERA \\ Universidad de Sevilla \\ tbarrera@us.es
}

\begin{abstract}
A
lvar Núñez Cabeza de Vaca fue héroe y víctima, conoció el éxito y el fracaso al norte y al sur del continente americano convirtiéndose, por la caprichosa fortuna, mal o bien enderezada, en un caso ejemplar de sufrimiento y penalidades, algo bastante habitual en la gesta americana. Y no solo por lo que relata en sus Naufragios (1555), donde un campo semántico de la desdicha se desprende del mismo: hambre, frío, muerte, dolor, lágrimas, temor, heridas, desventuras, miserias, durísimos trabajos, sufrimientos, etc. Por si fuera poco, a lo vivido en tierras americanas, tuvo que sumar su enjuiciamiento en España tras la expedición al sur. Padecimientos físicos y morales que actúan en eco y que convierten su caso en una pieza más de la mala fortuna que acompañó a buena parte de estos exploradores. Me referiré especialmente a los acontecimientos más relevantes de su periplo por tierras del actual sur de los Estados Unidos, aunque en honor a la verdad habría que apuntar que su actitud en Sudamérica varió mucho - especialmente frente al indígena - respecto a lo reflejado en Naufragios, quizás su posición diferente en una y otra expedición articulara su comportamiento; no es lo mismo el papel de un alguacil y tesorero que el de un gobernador.

Si hay un texto ejemplar en cuanto a las desdichas relatadas por el protagonista, sujeto receptor en primera persona junto a tres supervivientes, ese es el texto de Naufragios, uno más de una larga cadena de las infortunadas expediciones a la Florida, tierra tan esquiva como atractiva para aquellos que intentaron a lo largo del tiempo poseerla: «Desde que en 1512 don Juan Ponce de León descubrió la isla Florida, hasta la expedición de Hernando de Soto que regresaría malparada y estozada a México en 1542, todas estuvieron estigmatizadas por el fracaso» (Barrera, 2015: 9)1. Va a ser ese fracaso el motor desencadenante del
\end{abstract}

1 Todas las citas del texto están tomadas por esta edición.

Edad de Oro, XL (2021), pp. 187-201, ISSN: 0212-0429 - ISSNe: 2605-3314

DOI: https://doi.org/10.15366/edadoro2021.40.008 
texto, lo que le lleva a excusarse en el proemio y ofrecer su texto como prenda compensatoria.

Lo cual yo escreví con tanta certinidad, que aunque en ella se lean algunas cosas muy nuevas y para algunos muy difíciles de creer, pueden sin dubda creerlas: y creer por muy cierto que antes soy en todo más corto que largo, y bastará para esto averlo yo offrescido a Vuestra Majestad por tal. A la cual suplico la reciba en nombre de servicio, pues éste solo es el que un hombre que salió desnudo pudo sacar consigo (2015: 81).

La desnudez no es solo simbólica sino también física, como puede verse en los últimos capítulos. Cabeza de Vaca, protagonista y relator, selecciona lo que quiere contar y podemos decir que la lengua del afligido (nuestro protagonista) se ata y se desata, como diría Carneiro (2015). El jerezano cumple aquí un triple papel, es autor, relator y protagonista de la aventura, poseedor de un discurso marcado por unos intereses concretos: relatar sus padecimientos y engrandecer su figura ante el desastre. Sabe que, como relación de servicio, tiene una misión documental, pero al mismo tiempo es consciente de que el botín no existía, no habría compensación ni recompensa ni para sí ni para la Corona, no pudo darse «conforme a servicio» y así dice en el proemio.

Mas como ni mi consejo, ni diligencia, aprovecharon para que aquello a que éramos idos fuesse ganado conforme al servicio de Vuestra Magestad, y por nuestros peccados permitiesse Dios que de cuantas armadas a aquellas tierras han ido ninguna se viesse en tan grandes peligros ni tuviesse tan miserable y desastrado fin, no me quedó lugar para hacer más servicio deste, que es traer a Vuestra Majestad relación de lo que en diez años que por muchas y muy extrañas tierras que anduve perdido y en cueros, pudiesse saber y ver, ansí en el sitio de las tierras y provincias dellas, como en los mantenimientos y animales que en ella se crían, y las diversas costumbres de muchas y muy bárbaras naciones con quien conversé y viví, y todas las otras particularidades que pude alcançar y conocer, que dello en alguna manera Vuestra Magestad será servido, porque aunque la esperança que de salir de entre ellos tuve, siempre fue muy poca, el cuidado y diligencia siempre fue muy grande de tener particular memoria de todo, para que si en algún tiempo Dios nuestro Señor quisiesse traerme a donde agora estoy, pudiesse dar testigo de mi voluntad, y servir a Vuestra Magestad (2015: 80-81).

El texto resultante aúna lo documental y lo pragmático con lo creativo, y ambos comparten un nexo: el fracaso y la desnudez. Atendiendo a las reflexiones de Alburquerque (2015) estaríamos ante un libro que podría encuadrarse, de manera laxa, en la literatura de viaje desde el momento en que estamos ante una travesía por el sur de los actuales Estados Unidos, una expedición que pronto se convierte 
en peregrinación errática, que se mueve entre lo objetivo y lo subjetivo, y tiene un sentido testimonial.

el subrayado del «yo» como nueva autoridad frente a los clásicos, y una voluntad cada vez más acentuada de reflejar la realidad de un modo directo (el autor / narrador es un testigo de excepción), se potenciarán más adelante en algunas de las crónicas de Indias: el Diario de los viajes de Colón, sus Cartas a los Reyes, las Cartas de relación de Hernán Cortés, los Naufragios de Alvar Núñez Cabeza de Vaca (Alburquerque, 2015: 31).

\section{NAUfRAGAR, PRIMER ESTADIO DE LA DESNUDEZ}

Hasta llegar a la edición de 1555, esta obra no recibiría el atractivo título de $\mathrm{Nau}$ fragios, en esa edición se une a Comentarios y forma así el binomio completo de la trayectoria del jerezano por tierras del norte y sur de América, con sus luces y sus sombras. Tanto el rótulo «Naufragios» como el encabezamiento de los capítulos son frutos de la edición del 1555 (Adorno y Pautz, 1999: III, 91 y ss.). La elección del naufragio como denominador del texto puede ponernos en la pista de la importancia de la desventura marítima en aquellos momentos, pero no podemos olvidar que este motivo está ya en la literatura clásica: navegar y naufragar parece ser un maridaje habitual en los viajes por mar. Contar o relatar una tempestad que desemboca en naufragio es atractivo para el oyente y/o para el lector. Aunque podríamos citar varios ejemplos de la Antigüedad, quizás uno de los más conocidos esté contenido en la Eneida virgiliana que, como comenta Herrero Massari, es «el antecedente más autorizado del cuadro narrativo retórico completo y la fuente principal de los diversos tópicos que la componen» (1997: 206). En la España del XVI y del XVII abundarán sus muestras en obras que van desde el Persiles al Lazarillo, entre muchas. El camino para su utilización en relaciones o crónicas de viajes exploradores a lo largo y ancho del continente americano estaba servido.

No por casualidad, Gonzalo Fernández de Oviedo rotula el libro L del tomo V de su Historia General y Natural de las Indias con el sobrenombre de «Infortunios y Naufragios». El descubrimiento y conquista de las nuevas tierras americanas estuvieron marcadas por las dificultades del hecho en sí. No puede extrañarnos que los viajes marítimos conociesen el naufragio más de lo que hubiesen deseado. Con frecuencia las crónicas de la época insisten en los éxitos, en los logros y, esporádicamente, nos dan noticias de los fracasos por mar y por tierra. Como se ha apuntado «la peripecia del náufrago se desarrolla fuera del ámbito de la relación correspondiente. Su traumática salida de las huestes y su soledad en el territorio inhóspito lo circunscriben en una zona de silencio historiográfico» (Crovetto, 1993: 207). 
Gonzalo Fernández de Oviedo que, como es sabido, albergó la realización de una historia enciclopédica, no pudo ignorar estas calamidades y decide agruparlas en el libro final y último de su Historia General y Natural de las Indias: «Infortunios e naufragios acaescidos en las mares de las Indias, islas y Tierra Firme del mar Océano» y advierte en el proemio.

Determinado tengo de reducir en este último libro algunos casos de infortunios e naufragios e cosas acaescidas en la mar, así porque las que a mi noticia han venido, son cosas para oír e notarse, como porque los hombres sepan con cuántos peligros andan acompañados los que navegan. E si los que yo no he sabido ni aquí se escriben todos se hobiesen de decir, sería uno de los mayores tractados que en el mundo están escriptos e de mayor volumen; porque así como las mares son en diversas partes navegadas por diversas gentes e lenguas, así es imposible venir a noticia nuestra todo lo que en ella ha acaescido de semejantes cosas (1959: 305).

Era Oviedo un buen conocedor de lo que pasaba en las Indias, sus idas y venidas, sus propias vicisitudes personales lo avalan como avezado cronista que con tesón y minuciosidad acumuló notas y notas en Santo Domingo para luego pespuntear su magna Historia que en su totalidad no vería la luz en vida. Recoge Oviedo unas veintinueve expediciones marcadas por el desastre en la navegación entre 1513 y 1548 . No sabemos la interacción, si la hubo, entre los escritos de Oviedo y el relato de Cabeza de Vaca, pero no puede sorprender que encontremos similitudes y concordancias entre ambos - algunas detectadas por Maura (2013) - , ya que todos los relatos de naufragios coinciden, como hemos dicho, en una serie de elementos tópicos que se repiten desde la Antigüedad.

El naufragio en sí es una manifestación entre otras (peste, terremotos, muerte súbita, etc.) del infortunio o fortuna adversa, la caprichosa fortuna que si bien, por un lado, pone de relieve los designios de la providencia divina contra los que la voluntad humana no puede modificar; por otro, deja al descubierto la capacidad humana para enderezar y llevar a buen puerto el destino propio.

Mas ya que el desseo y voluntad de servir y a todos en esto haga conformes, allende la ventaja que cada uno puede hacer, ay una muy gran differencia no causada por culpa dellos, sino solamente de la fortuna, o más cierto sin culpa de nadie, más por sola voluntad y juizio de Dios; donde nasce que uno salga con más señalados servicios que pensó, y a otro le suceda todo tan al revés, que no pueda mostrar de su propósito más testigo que a su diligencia, y aun ésta queda a las vezes tan encubierta que no puede volver por sí (2015: 79-80).

Cabeza de Vaca se defiende y achaca a la caprichosa fortuna o incluso a la providencia divina su infortunio. Hablando de la fortuna en general, recuerda Sarissa Carneiro (2015) la obra de Girolamo Garimberto, Della fortuna libri sei (1547), 
que insiste en el poder que tiene esta en esferas muy distintas tales como la guerra, el juego y la navegación de la que habla Garimberto en el capítulo VIII del libro VI. Dicho libro fue traducido veinticinco años después por Juan Méndez de Ávila con el nombre de Teatro de varios y maravillosos acontecimientos de la mudable Fortuna (Salamanca, 1572), cuya edición se maneja aquí, y de él procede la siguiente cita:

Hay dos suertes de navegar, la una por necesidad y la otra por elección: y todas dos muy sujetas a la fortuna, y mayormente aquella por necesidad. Porque todas las veces que un hombre se halla necesitado de hacer un camino por mar, se halla también al doble sujeto a la fortuna: primeramente, porque el correr aquel peligro que suelen correr todos aquellos que por voluntad van por mar, y puesto que no puede elegir hombres prácticos, o de lugar oportuno, o de bajel seguro, o de tiempo conveniente, o de otras cosas necesarias a la navegación, es forzado de la necesidad a ponerse en todo a discreción de la fortuna. Y si el fin de su navegación fuera de llegar prósperamente en un puerto, aqueste sin otra cosa se deberá llamar verdaderamente afortunado. Y quien navegare por elección, se ponga a punto de cualquier cosa necesaria esperando la ocasión del buen tiempo, antes que salga del puerto y se ponga a contrastar con las ondas y con los vientos y llegando prósperamente al fin de su camino, se podrá decir también afortunado. Pero no tanto como aquél que no pudiéndose del juicio o del ingenio le conviene valerse solamente de la suerte, a donde esto otro se vale de lo uno y de lo otro justamente en el arte de navegar (1572: 169-170).

Indudablemente el libro de Garimberto es posterior a la primera edición del texto de Cabeza de Vaca (1542), pero no deja de ser una reflexión oportuna aplicable al jerezano, así como una buena sistematización de los naufragios aplicados al descubrimiento de tierras americanas en los que sin duda se inspiró. Cabeza de Vaca ilustra un caso aparte de navegar por elección, aunque a veces la necesidad puede estar y está detrás de una elección. Pormenorizados datos del naufragio son relatados en los capítulos iniciales, ya desde el capítulo I de Naufragios nos dice:

A esta hora el agua y la tempestad començó a crescer tanto, que no menos tormenta avía en el pueblo que en la mar, porque todas las casas e iglesias se cayeron, y era necessario que anduviéssemos siete o ocho hombres abraçados unos con otros para podernos amparar que el viento no nos llevasse; y andando entre los árboles, no menos temor teníamos dellos que de las casas, porque como ellos también caían, no nos matassen debaxo. En esta tempestad y peligro anduvimos toda la noche, sin hallar parte ni lugar donde media hora pudiéssemos estar seguros. Andando en esto oímos toda la noche, especialmente desde el medio della, mucho estruendo grande y ruido de bozes, y gran sonido de cascaveles y de flautas y tamborinos y otros instrumentos, que duraron hasta la mañana que la tormenta cesó. En estas partes nunca otra cosa tan medrosa se vio; yo hice una probança dello, cuyo testimonio 
enbié a Vuestra Magestad. El lunes por la mañana baxamos al puerto y no hallamos los navíos; vimos las boyas dellos en el agua, adonde conoscimos ser perdidos, y anduvimos por la costa por ver si hallaríamos alguna cosa dellos; y como ninguno hallássemos, metímonos por los montes, y andando por ellos un cuarto de legua de agua hallamos la barquilla de un navío puesta sobre unos árboles, y diez leguas de allí por la costa, se hallaron dos personas de mi navío y ciertas tapas de caxas, y las personas tan desfiguradas de los golpes de las peñas, que no se podían conocer; halláronse también una capa y una colcha hecha pedaços, y ninguna otra cosa paresció. Perdiéronse en los navíos sesenta personas y veinte cavallos (2015: 86-87).

Los primeros capítulos de la relación resultan un tour de force continuo frente al gobernador, destacando su imprudencia en contraste con los prudentes consejos de él mismo, tesorero y alguacil mayor. Aquí podríamos aplicar, según el Atlas Mnemosyne de Aby Warburg, una de las representaciones de la Fortuna, aquella que aparece con timón y vela para ejemplificar la lucha del protagonista con su destino.

Yo respondía que me parescía que por ninguna manera devía dexar los navíos sin que primero quedassen en puerto seguro y poblado, y que mirasse que los pilotos no andaban ciertos, ni se affirmavan en una misma cosa, ni savían a qué parte estavan; y que allende desto, los cavallos no estavan para que en ninguna necessidad que se ofresciesse nos pudiéssemos aprovechar dellos; y que sobre todo esto, ívamos mudos y sin lengua, por donde mal nos podíamos entender con los indios, ni saber lo que de la tierra queríamos, y que entrávamos por tierra de que ninguna relación teníamos, ni sabíamos de qué suerte era, ni lo que en ella avía, ni de qué gente estava poblada, ni a qué parte de ella estávamos; y que sobre todo esto, no teníamos bastimentos para entrar adonde no sabíamos. Porque visto lo que en los navíos avía no se podía dar a cada hombre de ración para entrar por la tierra más de una libra de vizcocho y otra de tocino, y que mi parecer era que se devía embarcar e ir a buscar puerto y tierra que fuesse mejor para poblar, pues la que avíamos visto, en sí era tan despoblada y tan pobre, cuanto nunca en aquellas partes se avía hallado. Al comissario le paresció todo lo contrario (2015: 93-94).

Desde el inicio de la navegación hasta que se pierden las naves definitivamente se sucederán los fracasos que ponen continuamente a prueba su resistencia frente a la adversidad. Comenta Margo Glantz que «el naufragio es una de las formas más refinadas del infortunio y entre sus maldiciones está la desnudez, alguna vez condición paradisíaca, aunque señal de desgracia en el mundo civilizado» (2006: 48). En el capítulo I, cuando están anclados en la isla de Trinidad, una tormenta les hace perder los navíos y gran número de gentes, como acabamos de ver. A partir de ahí y hasta el capítulo XII, tempestades, vientos contrarios y demás vicisitudes atmosféricas pondrán repetidamente en peligro sus vidas, hasta el punto de que el grueso de la expedición sucumbe por estas causas, como más tarde 
se sabrá. Cuando intentan regresar a España una tormenta les impide salir y otra los coge en la isla Bermuda «y toda una noche nos tuvimos por perdidos» (2015: 207). Las tormentas inician y escoltan el final de la aventura. Habitualmente unida al naufragio se constata la recurrencia de unos determinados tópicos, tales como las tempestades (capítulos I, II, V, VI, IX, entre otros) y el frío, que agrava aún más la situación calamitosa de los supervivientes, debido a la casi o total, a veces, ausencia de ropas. Aparece con frecuencia ligado al mal tiempo (capítulos IV, XII, XIV o XVI, entre otros): «Con mucho frío, sin osar entrar en la mar por la mucha tormenta que en ella avía» (2015: 115). Las tormentas, tan reiteradas en los relatos portugueses de naufragio, la Historia trágico-marítima, son descritas siguiendo un mismo patrón: vientos huracanados, averías de los barcos, olas gigantescas, cargas excesivas, escenas de desesperación, impericia de los pilotos (en este caso Diego Miruelo). Relatos medievales en latín, novelas de caballería o novelas bizantinas las contienen con prodigalidad. Acordamos con Herrero que «si algún hecho de la crónica histórica de los Siglos de Oro podía elevarse con todo merecimiento a la categoría de producto literario [...] era sin duda el de la tormenta marítima» (1997: 211).

Cabeza de Vaca nos persuade por medio de la representación de su infortunio, por un lado, gracias a su insistencia en las calamidades y padecimientos sufridos para conmover al lector, en primer lugar; a otras instancias superiores, después; a la Corona, en último término pero, por otro lado, sabe que no puede cargar las tintas para no aburrir, desconectar o hacer desconfiar al receptor, difícil equilibrio entre la realidad y la expresión de la misma que logra con éxito a lo largo de todo su texto, de ahí que, como decíamos al principio, su discurso se suelta y se controla al mismo tiempo, se expande y se constriñe, cuida lo que dice y cómo lo dice. Su narración es interesada, sin duda, y desde luego despierta emociones de compasión y conmiseración, quizás estuviera en su mente, al narrar, el interés que despertaría su texto, pero sus calamidades o desgracias fueron ciertas y no terminan en el naufragio, es solo una etapa de la desnudez.

\section{CAminar, Peregrinar, SEgundo ESTAdio DE LA DESNUdeZ}

Tras naufragar, su peripecia da lugar a una sustanciosa relación, sus aventuras en territorios indígenas le permiten mostrarse como avezado superviviente que desempeña los oficios más convenientes, según los casos, un ejemplo curioso de adaptación a un medio extraño, primero como mercader entre la costa y el interior, así «tenía libertad para ir donde quería y no era obligado a cosa alguna y no era esclavo» (2015: 134-135). Más tarde será curandero o chamán, sin olvidar en sus prácticas alguna oración cristiana. En suma, una adaptación al otro que no olvida su condición de hombre cristiano y civilizado, como prueba 
su rápida determinación de unirse a los de su condición cuando advierte rastros de españoles. Como viajero es traductor de la «otredad» y se sorprende por la multitud de lenguas de los indígenas llegando a expresiones como esta: «aunque sabíamos seis lenguas, no nos podíamos en todas partes aprovechar dellas porque hallamos más de mil diferencias» (2015: 190). Pese a ellos las muestras de vocabulario indígena que aporta el jerezano son escasas y atribuibles, en mi opinión, a la propia dinámica del relato caracterizado por la brevedad, por la síntesis, por la rapidez con que es relatada la peregrinación de tantos años. La propia construcción del relato determina una fuerte selección de lo que se quiere contar. Su contar es veloz, sintético, y continuamente apela a expresiones como «dexo aquí de contar esto más largo» (2015: 108), «y otras cosas que dexo de contar» (2015: 144), «Cuento esto assí brevemente» (2015: 113), los ejemplos podrían multiplicarse. Las razones de esta decidida intención de ser breve y escueto en su narrar pueden radicar en su condición de «relación».

Al mismo tiempo, esta peregrinación por lo que hoy es el sur de Estados Unidos le permitió el conocimiento directo de tribus indígenas en sus diversas costumbres e idolatrías, haciendo de su escritura una de las pioneras incursiones antropológicas que aún en la actualidad resultan válidas, ya que algunas de las tribus aquí descritas desaparecieron tempranamente. Este recorrido va a estar jalonado de sinsabores: el hambre y la sed van en aumento progresivo y en el capítulo XIV llegan a la antropofagia, sin matices alarmantes por parte del narrador.

$[\ldots]$ y de los cañales en que pescavan ya no avía provecho ninguno, y como las casas eran tan desabrigadas, començóse a morir la gente, y cinco christianos que estavan en el rancho en la costa llegaron a tal estremo que se comieron los unos a los otros, hasta que quedó uno solo, que por ser solo no huvo quien lo comiese. Los nombres de ellos son éstos: Sierra, Diego López, Corral, Palacios, Gonzalo Ruiz. Deste caso se alteraron tanto los indios, y ovo entre ellos tan gran escándalo, que sin dubda, si al principio ellos lo vieran, los mataran, y todos nos viéramos en grande trabajo; finalmente, en muy poco tiempo, de ochenta hombres que de ambas partes allí llegamos, quedaron vivos solos quince (2015: 127).

No deja de ser curioso que sean los indios y no los cristianos quienes se escandalicen del canibalismo cuando muchas culturas ancestrales han practicado la antropofagia.

Habría que reconocer, en primer lugar, que la práctica de los sacrificios humanos, muchas veces asociada a la antropofagia, estuvo presente no sólo entre los mexicas, o en Mesoamérica, incluyendo los mayas, sino que existió en casi todos los pueblos americanos, desde los esquimales en el norte hasta los araucanos en el sur (Martínez Baracs, 2010: s.p.) 
Un medio de supervivencia, como otros mencionados, fueron los caballos, comidos sin pudor y con frecuencia: «A veinte y dos días del mes de setiembre se acabaron de comer los cavallos» (2015: 111). Se vuelve sobre el canibalismo en el capítulo XVII donde comenta cómo ese «comestible» salvó a Esquivel: «y los que morían, los otros los hazían tasajos; y el último que murió fue Sotomayor, y Esquivel lo hizo tasajos, y comiendo dél se mantuvo hasta primero de março» $(2015: 141)$. No fue inusual la práctica del canibalismo en la conquista. En el texto de Ulrico Schmidel, Relato de la conquista del Río de la Plata y Paraguay (1534-1554), cuenta en el capítulo IX el episodio de unos soldados que mataron un caballo para comer y fueron ahorcados como castigo. Aquella noche unos soldados se acercaron a los ahorcados y les hicieron tasajos para alimentarse. Y termina diciendo cómo un español se comió al hermano que había muerto en la ciudad de Buenos Aires. Ahí está el grabado de Teodoro de Brye como prueba del episodio del canibalismo español en la ciudad de la Plata.

La fantasía e imaginación del jerezano se une a las evidencias que presenta para describir los males que le acosan y siempre resumiendo esas calamidades como si quisiera que el receptor lector las tuviese siempre presentes y no cayeran en el olvido. Así en el capítulo XVI dice:

Los trabajos que en esto passé sería largo de contarlos, assí de peligros y hambres, como de tempestades y fríos, que muchos dellos me tomaron en el campo y solo, donde por gran misericordia de Dios nuestro Señor escapé. [...] Fueron casi seis años el tiempo que yo estuve en esta tierra solo entre ellos y desnudo, como todos andavan (2015: 135).

Las mudanzas de la fortuna rigen en su peregrinación de mercader, pero también en su cautiverio, sobre todo por el trato desigual que reciben de las diversas tribus indígenas que le salen al paso. Entre los padecimientos corporales sobresalen el hambre y la sed, que se convierten en realidades inseparables de viaje. Desde el capítulo IV hasta que emprenden el camino del maíz, son fieles compañeras de los supervivientes. Normalmente unidas al frío, convierten su situación en extrema, viviendo al borde de la muerte de continuo, creciendo cada día. Indudablemente se ofrece todo un campo semántico de la desdicha con la repetición del hambre, frío, muerte, dolor, lágrimas, temor, heridas, desventuras, miserias, trabajos, sufrimientos, de forma incesante. Frente a este cúmulo de calamidades y padecimientos, destaca una estoica resistencia y unidad entre los supervivientes, buscando consuelo en Jesucristo y poniendo la lealtad al emperador por encima de todo. A veces por huir de una calamidad optan por enfrentarse a otra como cuando el hambre, y por ende el temor a la muerte, los empuja a navegar de nuevo y dice: 
cresciendo cada día la sed y la hambre, porque los bastimentos eran muy pocos e ivan muy al cabo, y el agua se nos acabó, porque las botas que hicimos de las piernas de los caballos luego fueron podridas y sin ningún provecho. Algunas veces entramos por ancones y baías que entravan mucho por la tierra adentro; todas las hallamos baxas y peligrosas. Y ansí anduvimos por ellas treinta días, donde algunas veces hallábamos indios pescadores, gente pobre y miserable. Al cabo ya de estos treinta días, que la necessidad del agua era en extremo, yendo cerca de la costa, una noche sentimos venir una canoa, y como la vimos, esperamos que llegasse, y ella no quiso hacer cara; y aunque la llamamos, no quiso bolver ni aguardarnos, y por ser de noche no la seguimos, y fuímonos nuestra vía. Cuando amaneció vimos una isla pequeña, y fuimos a ella por ver si hallaríamos agua; mas nuestro trabajo fue embalde, porque no la avía. Estando allí surtos, nos tomó una tormenta muy grande, porque nos detuvimos seis días sin que osássemos salir a la mar; y como avía cinco días que no bebíamos, la sed fue tanta, que nos puso en necessidad de beber agua salada, y algunos se desatentaron tanto en ello, que súbitamente se nos murieron cinco hombres. Cuento esto assí brevemente, porque no creo que haya necesidad de particularmente contar las miserias y trabajos en que nos vimos; pues considerando el lugar donde estávamos y la poca esperança de remedio que teníamos, cada uno puede pensar mucho de lo que allí passaría. Y como vimos que la sed crescía y el agua nos mataba, aunque la tormenta no era cessada, acordamos de encomendarnos a Dios nuestro Señor, y aventuramos antes al peligro de la mar que esperar la certinidad de la muerte que la sed nos dava (2015: 112-113).

\section{La desnudez ya no solo es simbólica sino también física.}

[...] y como ívamos desnudos y el frío que hazía era muy grande [...]. Los que quedamos escapados, desnudos como nascimos y perdido todo lo que traíamos, y aunque todo valía poco, para entonces valía mucho. Y como entonces era por noviembre, y el frío muy grande, y nosotros tales que con poca difficultad nos podían contar los huessos, estábamos hechos propia figura de la muerte. De mí sé dezir que desde el mes de mayo passado yo no avía comido otra cosa sino maíz tostado, y algunas vezes me vi en necesidad de comerlo crudo; porque aunque se mataron los cavallos entretanto que las barcas se hazían, yo nunca pude comer dellos, y no fueron diez veces las que comí pescado. Esto digo por escusar razones, porque pueda cada uno ver qué tales estaríamos (2015: 122-123).

En el capítulo XXI relata cómo el arder de unas zarzas le libera del frío de forma milagrosa.

[...] y yo quedé solo, y veniendo a buscarlos aquella noche me perdí, y plugo a Dios que hallé un árbol ardiendo, y al fuego dél pasé aquel frío aquella noche, y a la mañana yo me cargué la leña y tomé dos tizones, y bolví a buscarlos, y anduve desta manera cinco días, siempre con mi lumbre y carga de leña, porque si el fuego se me matasse en parte donde no tuviesse leña, como en muchas partes no la avía, 
tuviesse de qué hazer otro tizones y no me quedasse sin lumbre, porque para el frío yo no tenía otro remedio, por andar desnudo como nascí (2015: 152).

Huelga decir que el hambre no es privativa del grupo. Muchos de aquellos indios se mantenían de «raíces», como «nueces» que sacan del agua (XII, XXII). Otras veces pueden pasar tres días sin probar bocado (XV), en otros momentos la tuna se convierte en único alimento durante tres meses (XVII, XVIII). Todo es al fin y al cabo comestible: arañas, huevos de hormiga, gusanos, lagartijas, culebras y todo tipo de reptiles; también el estiércol de ganado, la tierra o la madera pueden servir de sustituto. La desnudez y el hambre se hacen omnipresentes en los capítulos centrales, sobre todo hasta que terminan la peregrinación involuntaria. El capítulo XXII tiene sobradas muestras.

Con éstos padescimos más hambre que con los otros, porque en todo el día no comíamos más de dos puños de aquella fruta, la cual estaba verde; tenía tanta leche, que nos quemava las bocas; y con tener falta de agua, dava mucha sed a quien la comía. Y como la hambre fuesse tanta, nosotros comprámosles dos perros y a trueco de ellos les dimos unas redes y otras cosas, e un cuero con que yo me cubría. Ya he dicho cómo por toda esta tierra anduvimos desnudos; y como no estávamos acostumbrados a ello, a manera de serpientes mudávamos los cueros dos veces en el año, y con el sol y el aire hacíansenos en los pechos e en las espaldas unos empeines muy grandes, de que rescebíamos muy gran pena por razón de las muy grandes cargas que traíamos, que eran muy pesadas; y hacían que las cuerdas se nos metían por los braços (2015: 159-160).

De gran plasticidad descriptiva es la forma de paliar el hambre cuando comenta, en el mismo capítulo, cómo comer las raeduras de cuero podía aplacarle unos días o cómo no se atrevían a asar un pedazo de carne, cuando lo había, por el miedo de que vinieran otros indios y se los robasen durante el proceso de asado.

Otras veces me mandaban raer cueros y ablandarlos. Y la mayor prosperidad en que yo allí me vi era el día que me davan a raer alguno, porque yo lo raía muy mucho y comía de aquellas raeduras, y aquello me bastava para dos o tres días. También nos acontesció con estos y con los que atrás avemos dexado, darnos un pedaço de carne y comérnoslo así crudo, porque si lo pusiéramos a assar, el primer indio que llegaba se lo llevaba y comía. Parescíanos que no era bien ponerla en esta ventura y también nosotros no estávamos tales, que nos dávamos pena comerlo asado, e no lo podíamos también pasar como crudo (2015: 160).

La dureza de la situación alcanza de este modo cotas inimaginables y el tamaño de la desventura crece. Y es que, efectivamente, ciertos indios no solo se sorprenden de la antropofagia, sino que incluso se compadecen de ellos cuando los ven de tal suerte. Con habilidad busca testigo de lo que dice y relata la reacción del «otro», a todas luces indemostrable, pero de gran patetismo escénico. 
Los indios, de ver el desastre que nos avía venido y el desastre en que estávamos, con tanta desventura y miseria, se sentaron entre nosotros, y con el gran dolor y lástima que ovieron de vernos en tanta fortuna, començaron todos a llorar rezio, y tan de verdad, que lexos de allí se podía oír, y esto les duró más de media hora; y cierto, ver que estos hombres tan sin razón y tan crudos, a manera de brutos, se dolían tanto de nosotros, hizo que en mí y en otros de la compañía cresciesse más la passión y la consideración de nuestra desdicha (2015: 124).

\section{EN TIERRA DE CRISTIANOS, DE LA DESNUDEZ AL VESTIDO}

A partir del capítulo XXXI parece cambiar la suerte: «Nosotros dimos muchas gracias a Dios nuestro Señor por avernos traído allí, donde avíamos hallado tanto mantenimiento [...] y de aquí passamos más de cien leguas de tierra, y siempre hallamos casas de assiento, y mucho mantenimiento de maíz, y frísoles, y dávannos muchos venados y muchas mantas de algodón, mejores que las de la Nueva España» (2015: 188).

En el capítulo siguiente recibirían más de seiscientos corazones de venados, poco después más mantas y a partir de ahí comienza a darse el cambio que coincide con señales de presencia próxima de cristianos. De la desnudez al abrigo. En el capítulo XXXIII las sospechas van afianzándose.

Después que vimos rastro claro de christianos, y entendimos que tan cerca estávamos de ellos, dimos muchas gracias a Dios nuestro Señor por querernos sacar de tan triste y miserable captiverio y el plazer que desto sentimos júzguelo cada uno cuando pensare el tiempo que en aquella tierra estuvimos y los peligros y trabajos por que passamos (2015: 196).

Todo lo vivido se agolpa de momento y el relator no quiere que el lector olvide lo sufrido por haber vuelto a la civilización, lo apela en ese «júzguelo cada uno». Han sido nueve años de penurias sin fin donde el hambre y la desnudez se hicieron protagonistas, muy especialmente en la isla de Malhado.

Cabeza de Vaca atraviesa un territorio ignoto en todas sus dimensiones, físicas y humanas, manteniendo una actitud pragmática siempre, guiado por el instinto de supervivencia, ajustándose a la realidad según la encuentre y cuidando, a pesar de todo, tener «particular memoria» de lo que ve. Todo esto contribuye al realce de sus dimensiones heroicas. Cual héroe picaresco se hará mercader «porque andando en él tenía libertad para ir donde quería y no era obligado a cosa alguna y no era esclavo» (2015: 134-135) o médico. Aunque los atributos de hombre civilizado hayan tenido que desaparecer, su asimilación al ambiente no es consustancial, pues nunca pierde el deseo de regresar a su mundo: «Y de mí sé dezir que siempre tuve esperança en su misericordia que me avía de sacar de aquella captividad» (2015: 154). 
Y aún se advierte cierto prurito de orgullo y superioridad frente a los indios cuando apunta que «teníamos con ello mucha autoridad y gravedad y para conservar esto les hablávamos pocas vezes» (2015: 190).

Cabeza de Vaca, que soñó durante tanto tiempo con el dorado deseo de volver con los cristianos, sale frustrado del primer encuentro. El recibimiento de Diego de Alcaraz y los suyos no pudo ser más desastroso. Se encuentra con un comportamiento inhumano y corrupto, hasta el punto de que el narrador se permite la siguiente reflexión: «donde paresce cuánto se engañan los pensamientos de los hombres, que nossotros andávamos a les buscar libertad y cuando pensávamos que la teníamos suscedió tan al contrario» (2015: 200).

Es en esta parte donde se manifiesta un Cabeza de Vaca colonizador, evangelizador, paladín de ese móvil conquistador y denunciante del comportamiento de los de su raza con la tierra y sus habitantes: «estas gentes todas, para ser atraídos a ser christianos y a obediencia de la Imperial Magestad, han de ser llevados con buen tratamiento, y que éste es camino muy cierto, y otro no» (2015: 194). No solo apunta métodos de colonización, sino las posibilidades de explotación de las tierras que atraviesa. Es curioso, también, ver cómo lo primero que pide cuando ve a los de su raza es día, mes y año de llegada (capítulo XXXIII), con lo que se inserta de nuevo en el tiempo de los hombres, el tiempo cronológico, frente a la atemporalidad de su vida robinsoniana.

En el capítulo XXXVI llegan a Compostela y se presentan al gobernador de Nueva Galicia, Nuño de Guzmán, que «nos rescibió muy bien y de lo que tenía nos dio de vestir» (2015: 206). La desnudez queda atrás, en el mundo de los salvajes. Al volver a la civilización, la cosa cambia. Se encaminarían luego a México donde tanto el virrey como Hernán Cortés les recibieron «con mucho placer» y fueron muy bien tratados, según expresión propia.

Con la llegada a España el sufrimiento físico de esta odisea quedó atrás, pero en la península le esperaba el sufrimiento moral, los sueños rotos al ver que el nombramiento de adelantado de la Florida no se lo dan a él, sino a Hernando de Soto, y aún más se acrecentó su infortunio con los sucesos posteriores, tras su expedición al Río de la Plata, cuando tras la muerte de Pedro de Mendoza consigue el puesto de adelantado. 
BiBLIOGRAFÍA

Adorno, Rolena y Patrick Charles Pautz (1999). Alvar Núñez Cabeza de Vaca: his account, his life, and the expedition of Pánfilo de Narváez. Lincoln / London: University of Nebraska Press.

Alburquerque, Luis (2015). «Poética de la literatura de viaje». En Daniar Chávez y Marco Urdapilleta (eds.), Cartografia de la literatura de viaje en Hispanoamérica. Ciudad de México: Universidad Nacional Autónoma de México, pp. 19-36.

CARneiro, Sarissa (2015). Retórica del infortunio. Persuasión, deleite y ejemplaridad en el siglo XVI. Madrid / Frankfurt am Main: Iberoamericana / Vervuert.

FernándeZ De Oviedo, Gonzalo (1959). Historia General y Natural de las Indias. Juan Pérez de Tudela (ed.). Madrid: Atlas.

Herrero Massari, José Manuel (1997). «El naufragio en la literatura de viajes peninsular de los siglos XVI y XVII». Revista de Filología Románica, 14: 2, pp. 205-214.

Crovetto, Pier Luigi et alii (1993). «El naufragio en el Nuevo Mundo: de la escritura formalizada a la prefiguración de lo novelesco». En Margo Glantz (coord.), Notas y comentarios sobre Alvar Núñez Cabeza de Vaca. Ciudad de México: Grijalbo, pp. 205-218.

Glantz, Margo (2006). «Épica y retórica del infortunio». En José Pascual Buxó (ed.), Permanencia y destino de la literatura novohispana. Ciudad de México: Universidad Nacional Autónoma de México, pp. 43-56.

MARTínez BARACS, Rodrigo (2010). «Sacrificio y antropofagia». Letras Libres [Consulta: 28/06/ 2020].

MAurA, Juan Francisco (2013). «El libro L de la Historia general y Natural de las Indias (Infortunios y Naufragios) de Gonzalo Fernández de Oviedo (1535): ¿génesis o inspiración de algunos episodios de Naufragios de Alvar Núñez Cabeza de Vaca (1542)?». Lemir, 17, pp. 87-100.

MÉNDEZ DE ÁvIlA, Juan (1572). Teatro de varios y maravillosos acontecimientos de la mudable Fortuna. Salamanca: s.e.

NúÑEz CABEZA de VACA, Alvar (2015). Naufragios. Trinidad Barrera (ed.). Madrid: Alianza Editorial.

Schmid, Ulrico (1986). Conquista del Río de la Plata y Paraguay, 1534-1554. Madrid: Alianza Editorial.

Warburg, Aby (2010). Atlas Mnemosyne. Madrid: Akal.

Recibido: 29/06/2020

Aceptado: 06/07/2020 


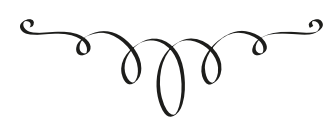

LA ADVERSA FORTUNA EN EL VIAJE DE CABEZA DE VACA POR TIERRAS NORTEÑAS

Resumen: Cabeza de Vaca es un caso paradigmático de los sufrimientos que llevaba aparejada la gesta americana en la mayoría de los casos. Lo que relata en sus Naufragios abarca el campo semántico de la desdicha ligado a la adversa fortuna: hambre, frío, muerte, dolor, lágrimas, temor, heridas, desventuras, miserias, trabajos, sufrimientos, etc. Padecimientos físicos y morales que actúan en eco.

PALABRAs ClaVes: Naufragio, fortuna, adversidad, fracaso, padecimientos físicos, padecimientos morales.

THE ADVERSE FORTUNE IN CABEZA DE VACA's EXPEDITION THROUGH NORTHERN LANDS

AbSTRACT: Cabeza de Vaca is a paradigmatic case of the sufferings that the American feat in most cases entailed. What he relates in his Naufragios covers the semantic field of misery: hunger, cold, death, pain, tears, fear, wounds, misadventures, miseries, jobs, sufferings, etc. Physical and moral ailments that act in echo.

KEYwORDS: Shipwreck, fortune, adversity, failure, physical suffering, moral suffering. 